\title{
ASSESSMENT ON KNOWLEDGE, ATTITUDE AND PRACTICE OF PHARMACOVIGILANCE AMONG THE HEALTHCARE PROFESSIONALS IN A TERTIARY HOSPITAL OF KATHMANDU
}

\author{
Shakya-Gurung $R$, Shrestha $D$, Thapa $R$
}

Department of Pharmacology, Nepal Medical College Teaching Hospital, Attarkhel, Gokarneswor-8, Kathmandu, Nepal

\begin{abstract}
Pharmacovigilance (PV) is the science and activities related to the detection, assessment, understanding and prevention of adverse effects. Healthcare professionals (HCPs) have an important role in reporting Adverse Drug Reaction (ADR) cases. However under-reporting has been a major challenge in PV. Hence, we assessed the knowledge, attitude and practice (KAP) of HCPs about PV in a tertiary hospital of Kathmandu. A cross-sectional study was conducted using pretested questionnaire consisting of 21 closed ended questions (twelve on knowledge, five on attitude, four on practice and one open ended question to know the causes of under-reporting. Out of 520 HCPs, 448 (207 doctors and 241 nurses) participated in the study with the response rate of $86.2 \%$. The mean KAP score for doctors was $10.38 \pm 2.68$ and $9.60 \pm 2.32$ for nurses. The major barriers for under-reporting were identified as the difficulty in deciding if it's an ADR and lack of time to report ADRs. No significant correlation between knowledge and attitude of the HCPs was found $(\mathrm{r}=0, \mathrm{n}=448, \mathrm{p}<0.01)$. However, there was a weak positive correlation between knowledge and practice $(\mathrm{r}=$ $0.05, n=448, p<0.01)$ and also for attitude and practice $(r=0.09, n=448, p<0.01)$. Hence, the HCPs had poor knowledge and practice but positive attitude towards PV. It is therefore strongly recommended to have an immediate educational intervention among the HCPs to improve the spontaneous ADR reporting.
\end{abstract}

\section{KEYWORDS}

Adverse drug reaction, attitude, knowledge, Nepal, pharmacovigilance, practice

\section{CORRESPONDING AUTHOR}

Mrs. Rashmi Shakya Gurung

Lecturer, Department of Pharmacology

Nepal Medical College Teaching Hospital, Attarkhel,

Gokarneswor-8, Kathmandu, Nepal.

Email: shakya.rushmee@gmail.com 


\section{INTRODUCTION}

Drugs are a boon to the mankind but their use is often associated with unavoidable and undesirable adverse drug reactions (ADRs). The WHO defines ADR as "a response to a drug which is noxious and unintended, and which occurs at doses normally used in man for the prophylaxis, diagnosis, or therapy of disease, or for modifications of physiological function"1 ADRs are regarded as one of the major reason of morbidity and mortality all over the world. ${ }^{2}$ It has been shown that around 2.9$5.6 \%$ of all the hospital admissions are due to ADRs and $35.0 \%$ of the hospitalized patients experience an ADR during their hospital stay. ${ }^{3}$ Thus, safe use of medicine is an important aspect in healthcare practice.

Detection of ADRs is a challenging issue. Animal toxicological studies and pre-clinical trials done in humans before the drug is marketed cannot reflect all the drug related hazards. Previously unidentified ADRs can occur when the drugs are used in the general population. Post marketing surveillance of drugs is thus important for the identification of unseen ADRs and should be an inevitable part of clinical practice. ${ }^{4}$ Doctors, nurses, pharmacists and pharmacologists play an important role in the identification of such unseen ADRs. ${ }^{5}$

Pharmacovigilance (PV) is "the science and the activities which relate to the detection, assessment, understanding and prevention of adverse effects or any other drug-related problems". ${ }^{1}$ The aims of PV are: assessing, collecting, monitoring, researching and evaluating ADRs related information; the ultimate goal being the safe use of drugs. ${ }^{6,7}$ Thus, PV is important for reducing morbidity and mortality related to ADRs.

The National Centre for PV in Nepal is regulated by the Department of Drug Administration since 2004 to liaison with WHO collaborating centre for International Drug Monitoring located in Sweden. Nepal became a member of the International PV program in $2006{ }^{8,9}$ At present, there are twelve regional pharmacovigilance centres in Nepal which report the collected data on suspected ADRs via an online system called 'vigiflow' ${ }^{10}$

Nepal Medical College and Teaching Hospital (NMCTH) was recognized as one of the regional centers since 2007. As few as 40 reports of ADRs have been collected so far..$^{11}$ Thus, under-reporting of ADRs is a major problem in this reporting centre. This can be due to gaps in the knowledge, attitude and practice (KAP) of PV among healthcare professionals (HCPs). Studies done to assess KAP of PV among HCPs had shown lack of awareness and knowledge as an important barrier in the reporting of ADR. ${ }^{6,11,12}$

This questionnaire based study was conducted to assess the KAP of HCPs about PV and also to identify the factors for under-reporting of ADR in NMCTH.

\section{MATERIALS AND METHODS}

This study was a questionnaire-based cross sectional study which was conducted in a tertiary hospital NMCTH from November 2017 to May 2018 to evaluate KAP among doctors and nurses working in NMCTH. NMCTH is a 700 bedded tertiary care teaching hospital in the capital city of Nepal, Kathmandu. The study was approved by the Institutional Review Committee. The study population was 520 HCPs (270 doctors and 250 nurses) working in the hospital during the study period. The study tool used was a pre-designed questionnaire which was adopted from previous studies with minor modifications done as per needed according to our hospital., ${ }^{2,12-14}$ The questionnaire consisted of 22 questions (twelve related to knowledge, five related to attitude and four related to practice). Each correct answer and each positive response was given a score of 1 whereas incorrect answer and negative response was given a score of 0 ; maximum possible score being 21. KAP was assessed and calculated by adding up the knowledge, attitude and practice scores for all the provided 21 questions. One question was asked to determine the causes of under-reporting an ADR. The participants were contacted directly in the department during their departmental activities. After explaining the aims of the study, they were invited to participate. Upon agreeing to participate, a written consent form was obtained from them ensuring their anonymity and confidence. The participants were given sufficient time to complete the questionnaires. Some of the questionnaires were filled instantly on the same day but some of them were collected on a different day because of the busy schedule of the participants.

The collected data were then entered into Statistical Package for Social Sciences (SPSS) version 16 for windows. Shapiro-Wilk test was used to test the normality of data distribution. Mann-Whitney U test was used to compare the median scores of KAP between two categorized groups: doctors and nurses. Scores more than or equal to half of the maximum score was considered as good score and the rest as bad score i.e. score of 6 or more for knowledge, 2.5 or more for attitude and 2 or more for practice was considered as good score. The good and bad KAP scores were then compared between the study groups using chi-square test. Spearmen correlation was used to check the co-efficient linear association between variables. P-value less than 0.05 was considered as statistical significance.

\section{RESULTS}

A total of 520 HCPs (270 doctors and 250 nurses) were working on the hospital at the time of study. Of those, 448 (207 doctors and 241 nurses) participated with a response rate of $86.2 \%$.

\section{HCPs' knowledge of PV}

While assessing the HCPs' knowledge of PV, it was found that majority of the HCPs had knowledge 


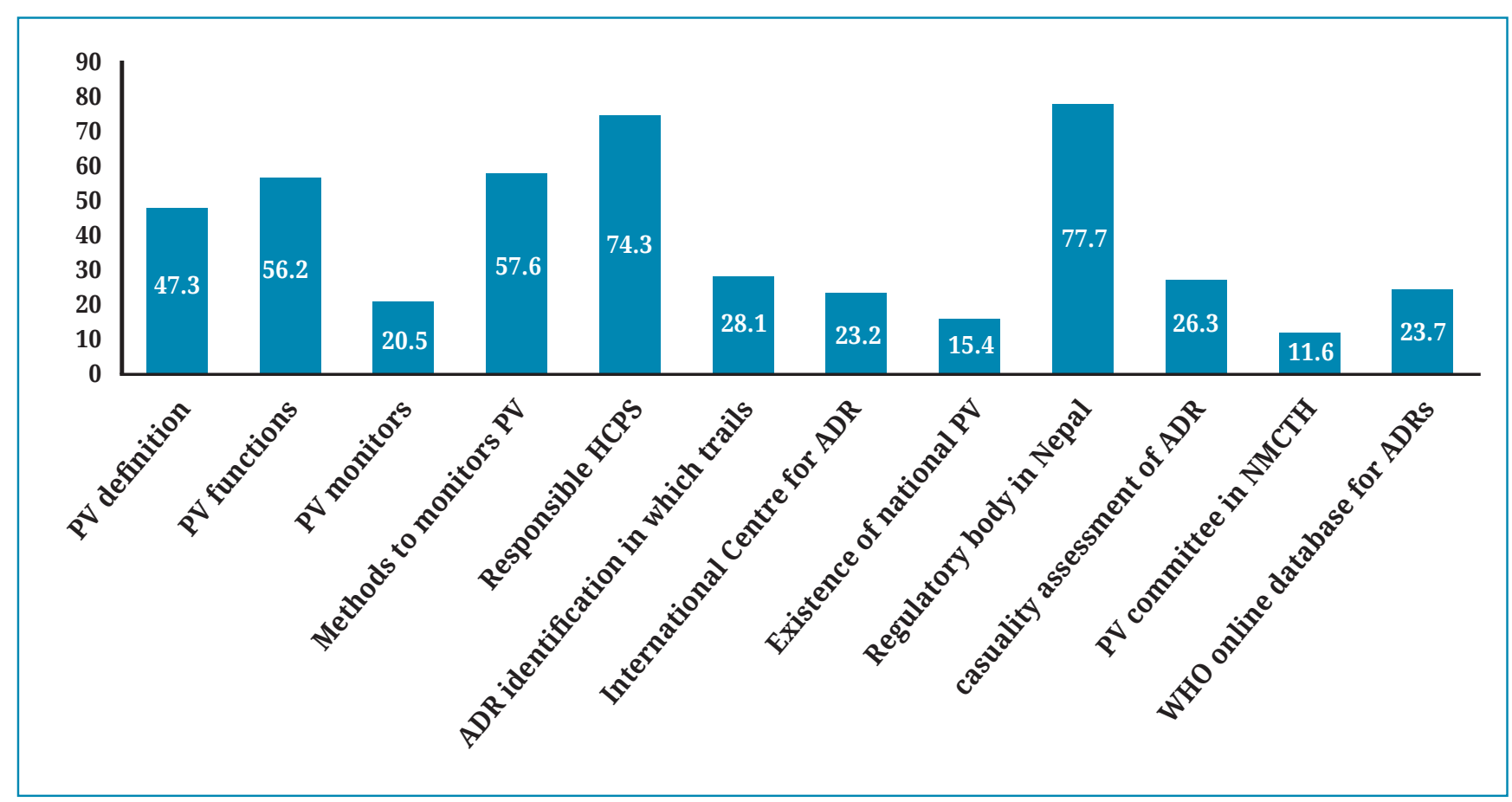

Fig. 1: HCPs' response towards knowledge-related questions

about who can report an ADR (74.3\%) and about the regulatory body for monitoring ADRs in Nepal (77.7\%). Less known aspects were the existence of national PV centre (15.4\%) and existence of PV committee in NMCTH (11.6\%) (Fig. 1).

\section{HCPs' attitude towards PV}

The participants showed positive attitude towards PV. $94.4 \%$ of the participants thought that reporting an ADR is necessary while $81.5 \%$ opined that PV centre should be established in every hospital. 76.6\% thought that reporting an ADR is a professional obligation for them so $84.6 \%$ felt that ADR reporting should be made mandatory. Also $88.6 \%$ of the participants believed that PV should be taught in detail to HCPs (Fig. 2).

\section{HCPs' practice regarding PV}

As far as practice was concerned, only $15.2 \%$ of the participants were trained on ADR reporting. 49.1\% of the participants had come across an ADR but only 4.9\% had ever reported an ADR to the PV centre in the institute. The practice of reading article was however seen more in HCPs (38.4\%) (Fig. 3).

\section{Factors causing under-reporting of ADR}

The most important factors that discouraged HCPs from reporting an ADR was found to be difficulty in deciding if its an ADR (33\%) and lack of time to report an ADR (29.7\%) (Fig. 4).

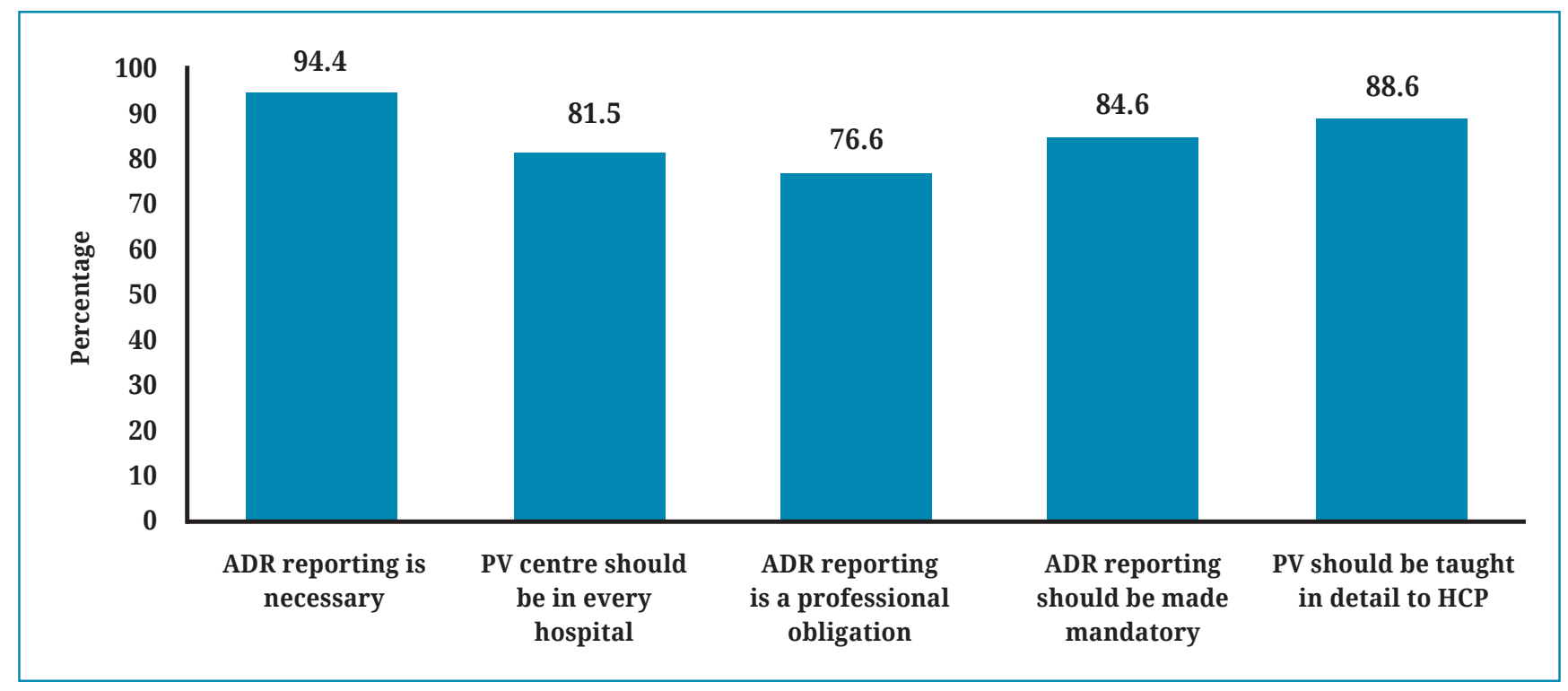

Fig. 2: HCPs' response towards attitude related questions 


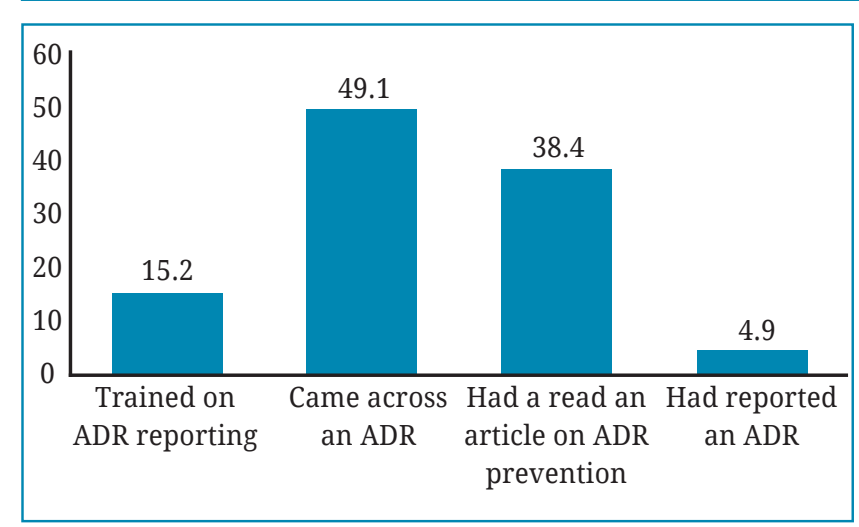

Fig. 3: HCPs' response to practice related questions nurses. It was found that the difference between median KAP scores among doctors and nurses were statistically significant $(p=0.00, p<0.05)$.

Comparison of good and bad KAP scores between doctors and nurses was done using Chi-square test. There was statistical significant difference between the two study groups for knowledge $(\chi 2=0.007$, $\mathrm{p}<0.05)$.

Spearman correlation coefficient was calculated to correlate the relationship of knowledge with attitude, knowledge with practice and attitude with practice. The calculations showed there was no significant correlation between knowledge and attitude of the

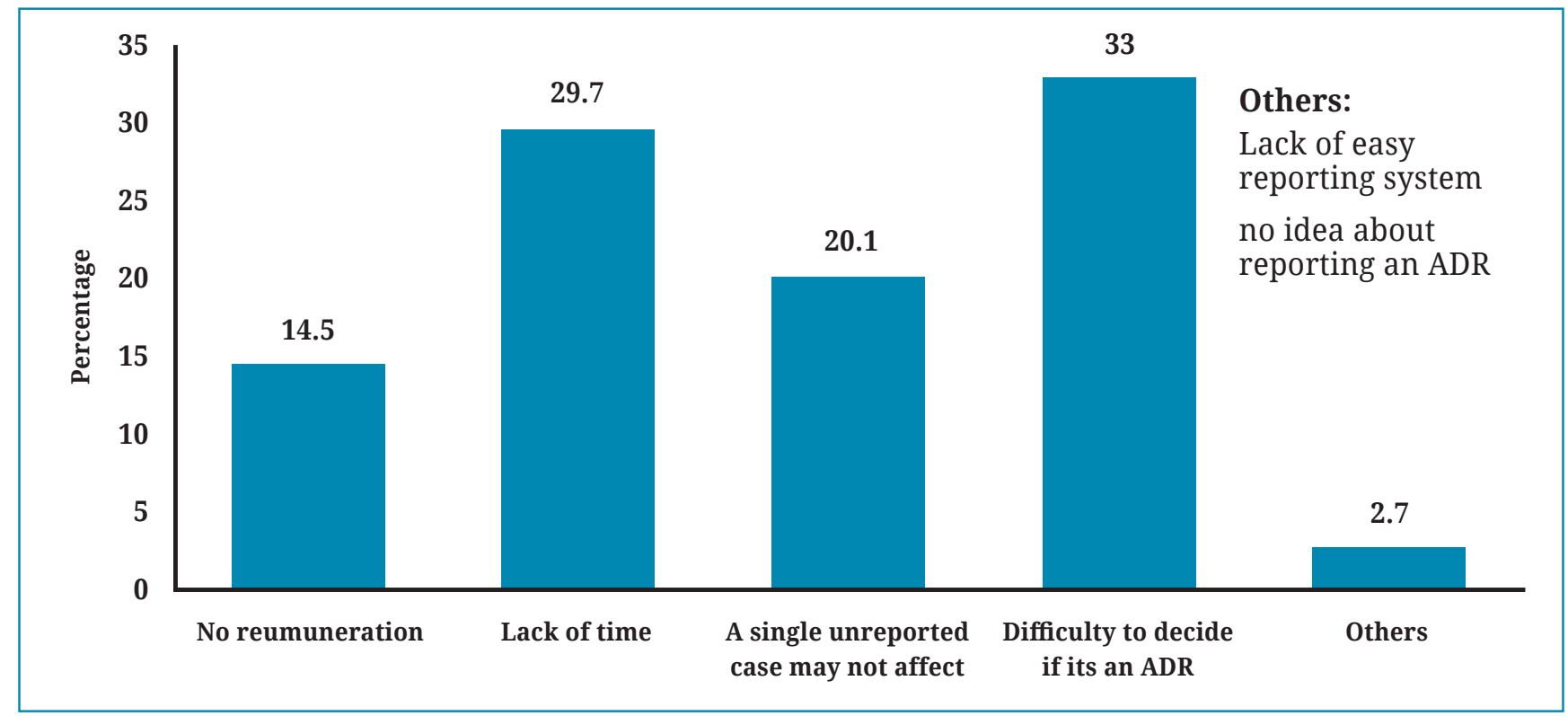

Fig. 4: Factors causing under-reporting among HCPs

Table-1: Comparison of mean KAP scores among doctors and nurses

\begin{tabular}{|lcccc|}
\hline \multicolumn{5}{c}{ Table-1: Comparison of mean KAP scores among doctors and nurses } \\
Profession & \multicolumn{4}{c|}{ Mean \pm SD Score } \\
& $\begin{array}{c}\text { Knowledge } \\
\text { [Max 12] }\end{array}$ & $\begin{array}{c}\text { Attitude } \\
\text { [Max 5] }\end{array}$ & Practice & Total Score \\
[Max 4] & [Max 21] \\
Doctors (N=207) & $4.84 \pm 1.87$ & $4.38 \pm 1.09$ & $1.15 \pm 0.86$ & $10.38 \pm 2.68$ \\
Nurses (N=241) & $4.43 \pm 1.6$ & $4.15 \pm 1.08$ & $1.00 \pm 1.02$ & $9.60 \pm 2.32$ \\
Overall [N=448] & $4.62 \pm 1.78$ & $4.25 \pm 1.08$ & $1.07 \pm 0.95$ & $9.95 \pm 2.52$ \\
\hline
\end{tabular}

5. Comparison of KAP scores among doctors and nurses

The mean knowledge, attitude and practice scores of the doctors were higher than the nurses. The mean KAP scores of the participants were categorized based upon profession (Table 1).

The KAP score was found not to be normally distributed after applying the Shapiro-Wilk test $(p<0.05)$. Thus, median was used as the measure of central tendency. The overall median-KAP score for doctors was $10 \pm 0.5$ (Median \pm QD) and $9 \pm 1.5$ for nurses. Mann-Whitney U test was then applied to compare median KAP scores among doctors and participants $(r=0, n=448, p<0.01)$. However, there was a weak correlation between knowledge and practice $(\mathrm{r}=0.05, \mathrm{n}=448, \mathrm{p}<0.01)$ and also for attitude and practice $(r=0.09, n=448, p<0.01)$.

\section{DISCUSSION}

Spontaneous reporting is an important method in reporting an ADR in PV programme and underreporting is major challenge. Assessing the KAP of PV among the HCPs is thus very important specially in a Regional PV Centre as it will ensure the extent of correct knowledge, right attitude and proper 
Table-2: Comparison of median KAP scores between doctors and nurses

\begin{tabular}{lccccccc|}
$\begin{array}{l}\text { Knowledge } \\
\text { (Max Score 12) }\end{array}$ & Occupation & Q1 & Median & Q3 & $\begin{array}{c}\text { Min } \\
\text { score }\end{array}$ & $\begin{array}{c}\text { Max } \\
\text { score }\end{array}$ & $\begin{array}{c}\text { Mann-Whitney U } \\
\text { test P-value }\end{array}$ \\
& Doctor & 4 & 5 & 6 & 0 & 10 & 0.006 \\
Attitude & Nurse & 3 & 4 & 5 & 1 & 10 & \\
(Max Score 5) & Doctor & 4 & 5 & 5 & 0 & 5 & 0.001 \\
Practice & Nurse & 4 & 4 & 5 & 0 & 5 & \\
(Max Score 4) & Doctor & 1 & 1 & 2 & 0 & 3 & 0.018 \\
\hline
\end{tabular}

Table-3: Comparison of good and bad KAP scores between doctors and nurses

\begin{tabular}{|c|c|c|c|c|}
\hline \multicolumn{2}{|c|}{ KAP } & \multicolumn{2}{|c|}{ Score } & \multirow{2}{*}{$\begin{array}{c}\text { Chi-square } \\
\text { P-value }\end{array}$} \\
\hline & & Good & Bad & \\
\hline \multirow{2}{*}{ Knowledge $\mathrm{n}(\%)$} & Doctor & $71(34.3 \%)$ & $136(65.7 \%)$ & \multirow{2}{*}{0.01} \\
\hline & Nurse & 55 (22.8\%) & $186(77.2 \%)$ & \\
\hline \multirow{2}{*}{ Attitude n (\%) } & Doctor & $190(91.8 \%)$ & $17(8.2 \%)$ & \multirow{2}{*}{0.45} \\
\hline & Nurse & $223(92.5 \%)$ & $18(7.5 \%)$ & \\
\hline \multirow{2}{*}{ Practice n (\%) } & Doctor & $71(34.3 \%)$ & $136(65.7 \%)$ & \multirow{2}{*}{0.16} \\
\hline & Nurse & $71(29.5 \%)$ & $170(70.5 \%)$ & \\
\hline
\end{tabular}

practice of HCPs in reporting an ADR. In Nepal, few studies have been done so far. ${ }^{6,13}$

Present study showed poor knowledge regarding various aspects of PV among HCPs specially amongst the nurses. Findings related to the knowledge in the present study were strikingly similar with the studies carried out in countries like China, Yemen, Pakistan, India, Iran, Nigeria and Malaysia. ${ }^{15-22}$ This might be because the PV programme in these countries including Nepal is still at its developing phase. However, in countries of South East Europe, the knowledge among the HCPs was good enough but underreporting of ADR was still a challenge in these countries as well. ${ }^{23}$ This difference can be associated with the way the healthcare system operates in the European countries; the PV programme were started very early there so that these countries have well established reporting system.

Present study revealed that the HCPs had a very positive attitude towards ADR reporting. 94.4\% of the participants opined that reporting an ADR is necessary while $84.6 \%$ of them felt that it should be made compulsory. So it means that the HCPs very well understand the importance of ADR reporting. Comparison with the results published in various studies also had similar findings. ${ }^{18,24}$ Similarly, the present study showed that $81.5 \%$ of the participants stressed on the idea that PV centre should be in every hospital and $88.6 \%$ of the participants believed that PV should be taught in detail to HCP. The result obtained is in agreement with studies done by Gupta et al and Rajalakshi et al who came up with the similar findings. ${ }^{25,26}$
The results obtained in the present study demonstrated that there wass a huge gap between ADRs experienced and ADRs being reported. 49.1\% of the participants had observed an ADR but only $4.9 \%$ of them had ever reported an ADR to PV centre. Various studies done had also revealed such a huge difference in ADR experienced and reporting. KC et al had also found out similar results; out of $74.8 \%$ of ADR experienced only $20 \%$ of the cases were reported in their findings. ${ }^{6}$ Similarly studies done by Torwane et al, Gupta et al, Pimpalkhute et al, Datta et al also showed unsatisfactory practices on ADR reporting; ADRs being reported in their studies were $6.1 \%,{ }^{18} 22.8 \%,,^{25} 25.0 \%,,^{27}$ and $24.0 \%,{ }^{28}$ respectively. But in countries like England and Sweden, the reporting rate is as high as $70 \%$ as reporting is mandatory there. ${ }^{17}$

The present study showed that the difficulty in deciding if its an ADR and lack of time as major factors that discouraged the HCPs from reporting an ADR. The results found were similar to the studies done in countries like India, China, Malaysia and Nigeria. ${ }^{2,15,21,22,29}$ In contrast, most of the studies done in European countries like England, Ireland, Portugal, Sweden, and United States had identified Complacency (belief that seirous ADRs are well documented when the drug is marketed) and fear of litigation as the most important causes of underreporting. ${ }^{30-34}$ It is mandatory by law for HCPs in Sweden to report suspected ADRs to authorities, the fear of getting involved in a lawsuit can therefore be one of the most important cause for underreporting in this country. ${ }^{35}$ 
In conclusion, the present study revealed that the HCPs had poor knowledge and poor practice of ADR reporting. However, the attitude towards the PV was very good. So, lack of knowledge among the HCPs seems to be the main barrier in the PV programme in this RPC. There is a need for HCPs to be sensitized about the importance of PV programmes, their responsibilities and process of reporting ADRs. Also, the spontaneous ADR reporting can further be improved by carrying out continuous medical education (CME), regular workshops, training and periodic awareness programme to keep them encouraged to report ADRs in the future. Further, measures to make PV an integral part of their clinical practice can be applied. Early sensitization of HCPs can be done by incorporating chapters of PV in both undergraduate and postgraduate curriculum. Practically too the medical students should be taught on filling the ADR reporting form.

\section{ACKNOWLEDGEMENT}

We would like to thank all the participants, Dr. Smriti Singh, Assistant Professor, Department of Physiology for her help in sample collection and Ms. Anishma Karmacharya for her help in writing this paper.

\section{REFERENCES}

1. World Health Organization. Fact sheet: safety of medicines. A guide to detecting and reporting adverse drug reactions. Geneva: 2002. WHO/EDM/ QSM/2002.

2. Gupta SK, Nayak RP, Shivaranjani R, Vidyarthi SK. A questionnaire study on the knowledge, attitude and the practice of pharmacovigilance among the healthcare professionals in a teaching hospital in South India. Perspect Clin Res 2015; 6: 45-52.

3. Baniasadish S, Fahimi F, Shalviri G. Developing an adverse drug reaction reporting system at a teaching hospital. Basic Clin Pharmacol Toxicol 2008; 102: 408-11.

4. Dhara RS, Dhande PP, Karandikar YS, Sahasrabudhe RA, Pandit VA. Impact of series of interventions on clinicians' awareness about pharmacovigilance system in Western India. Asian J Pharm Clin Res 2014; 7: 14-20.

5. Sharma HL, Sharma KK. Drug discovery and clinical evaluation of new drugs. Hyderabad: Paras Medical Publisher; 2010.

6. KC Santosh, Tragulpiankit P, Gorsanan P, Edwards IR, Alam K. Strenthening the pharmacovigilance programme in Nepal. Nepalese J Epdemiol 2013; 3: 230-5.

7. Suke SG, Kosta P, Negi H. Role of pharmacovigilance in India: Overview. Online J Public Health Inform 2015; 7: e223.

8. Memebers of the WHO programme for International Drug Monitoring. Available from: http://www.whoumc.org// [Accessed 12 ${ }^{\text {th }}$ May 2018].

9. Jha N, Shankar PR, Bajracharya O, Gurung SB, Singh KK. Adverse drug reaction reporting in a pharmacovigilance centre of Nepal. Australas Med J 2012; 5: 268-71.

10. Department of Drug Administration. Pharmacovigilance. Available from: http://www. dda.gov.np// [Accessed 15 th June, 2018].

11. Bista D, Shrestha BR, Rai P, Jauhari AC, Kulshrestha VK. Pattern of adverse drug reactions reported to the regional pharmacovigilance centre at Nepal Medical College and Teaching Hospital, Kathmandu. J Nepal Phar Assoc 2012; 26: 54-61.

12. Abdul Aslam P, Shajahan J, Purushothaman S. Awareness of pharmacovigilance and adverse drug reactions among second professional MBBS students of a medical college in Kerala, India. Int $J$ Basic Clin Pharmacol 2017; 6: 2911-5.

13. Palaian S, Ibrahim MI, Mishra P. Health professionals knowledge, attitude and practices towards pharmacovigilance in Nepal. Pharm Pract 2011; 9: 228-35.

14. Hardeep, Bajaj JK, Rakesh K. A survey on the knowledge, attitude and the practice of pharmacovigilance among the health care professionals in a teaching hospital in northern India. J Clin Diagn Res 2013; 7: 97-9.

15. Li Q, Zhang SM, Chen HT et al. Awareness and attitudes of healthcare professionals in Wuhan, China to the reporting of adverse drug reactions. Chin Med J 2004; 117: 856-61.

16. Alshakka M, Bassalim H, Alsakkaf Ket al. Knowledge and Perception towards Pharmacovigilance among Healthcare Professionals in Tertiary Care Teaching Hospital in Aden, Yemen. J Pharm Prac Community Med 2016; 2: 21-8.

17. Nisa ZU, Zafar A, Sher F. Assessment of knowledge, attitude and practice of adverse drug reaction reporting among healthcare professionals in secondary and tertiary hospitals in the capital of Pakistan. Saudi Pharm J 2018; 26: 453- 61.

18. Torwane AN, Sudhir H, Gouraha A, Jain S, Chavan K, Dayma A. Assessment of knowledge, attitude and practice related to pharmacovigilance among the healthcare professionals in a teaching hospital in central India: an questionnaire study. World $J$ Pharm Pharm Sci 2015; 4: 785-99.

19. Khan SA, Goyal C, Chandel N, Rafi M. Knowledge, attitudes and practice of doctors to adverse drug reaction reporting in a teaching hospital in India: an observational study. J Nat Sci Biol Med 2013; 4: 191-6.

20. Hanafi S, Torkamandi H, Hayatshahi A, Gholami K, Javadi M. Knowledge, attitudes and practice of nurse regarding adverse drug reaction reporting. Iran J Nurs Midwifery Res 2012; 17: 21-5.

21. Oshikoya KA, Awobusuyi JO. Perceptions of doctors to adverse drug reaction reporting in a teaching hospital in Lagos, Nigeria. BMC Clin Pharmacol 2009; 9: 14-22.

22. Aziz Z, Siang TC, Badarudin NS. Reporting of adverse drug reactions: Predictors of under- 
reporting in Malaysia. Pharmacoepidemiol Drug Saf 2007; 16: 223-8.

23. Kozamernik B. Spontaneous adverse drug reaction reporting: attitudes and practice of healthcare professionals and distributors in South East European region. Farm vestn 2010; 61: 271-81.

24. Kunnoor NS, Sharanabasappa S, Lohit K. Perception of doctors towards adverse drug reaction (ADR) reporting: a cross sectional survey using a validated questionnaire. Int J Basic Clinical Pharmacol 2017; 6: 2671-5.

25. Gupta P, Udupa A. Adverse drug reaction reporting and pharmacovigilance: knowledge, attitudes and perceptions amongst resident doctors. J Pharm Sci \& Res 2011; 3: 1064-9.

26. Rajalakshmi R, Vasudharadevi B, Prasad TSD, Swetha S, Dharini B. Knowledge, attitude and practice towards pharmacovigilance and adverse drug reaction reporting among nurses in a tertiary care hospital, tirupati. Int J Pharm \& Clin Res 2017; 9: 683-9.

27. Pimpalkhute SA, Jaiswal KM, Sontakke SD, Bajait CS, Gaikwad A. Evaluation of awareness about pharmacovigilance and adverse drug reaction monitoring in resident doctors of a tertiary care teaching hospital. Indian J Med Sci 2012; 66: 55-61

28. Datta S, Sengupta S. An evaluation of knowledge, attitude and practice of adverse drug reaction reporting in a tertiary care teaching hospital of Sikkim. Perspect Clin Res 2016; 6: 200-6.
29. Srinivasan V, Sheela D, Mridula D. Knowledge, attitude and practice among the healthcare professionals in a tertiary care hospital. Biomed Pharmacol J 2017; 10: 1441-7.

30. Belton KJ. European Pharmacovigilance Research group: Attitude survey of adverse drug-reaction reporting by healthcare professionals across the European union. Eu J Clin Pharmacol 1997; 52: 4237.

31. Vallano A, Cereza G, Pedros C, Agusti A, Danes I, Aguilera C et al. Obstacles and solutions for spontaneous reporting of adverse drug reactions in the hospital. Br J Clin Pharmacol 2005; 60: 653-8.

32. Herdeiro MT, Figueiras A, Polonia J, Gestal- Otero JJ. Influence of pharmacists' attitudes on adverse drug reaction reporting: a case-control study in Portugal. Drug Saf 2006; 29: 331-40.

33. Ekman E, Backstrom M. Attitudes among hospital physicians to the reporting of adverse drug reactions in Sweden. Eur J Clin Pharmacol 2009; 65: 43-6.

34. Gavaza P, Brown CM, Khoza S. Texas pharmacists' opinions on reporting serious adverse drug events to the Food and Drug Administration: a qualitative study. Pharm World Sci 2010; 3: 651-7.

35. Backstrom M, Ekman E, Mjorndal T. Adverse drug reaction reporting by nurses in Sweden. Eur J Clin Pharmacol 2007; 63: 613-8. 